\title{
Pacto do Ensino Médio: anseios, reflexões e perspectivas de professores sobre o ensino de Ciências da Natureza
}

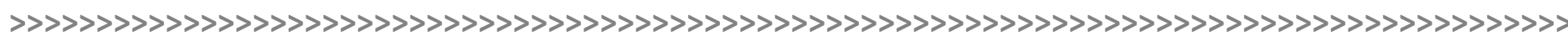

\author{
Vera Lucia Bobrowski* \\ Paulo Romeu Gonçalves** \\ Rosangela Ferreira Rodrigues ${ }^{* * *}$ \\ Geonir Machado Siqueira*** \\ Beatriz Helena Gomes Rocha**** \\ Luciana Bicca Dode ${ }^{* * *}$
}

\section{Resumo:}

O “Pacto Nacional pelo Fortalecimento do Ensino Médio (PNEM) representa a articulação e coordenação de ações e estratégias entre a União e os governos estaduais na formulação e implementação de políticas para elevar o padrão de qualidade do Ensino Médio brasileiro". Atividades de formação continuada em Ciências da Natureza foram desenvolvidas, as quais se alicerçaram nos pressupostos recomendados de conexão entre as ações existentes e novas proposições. A partir da análise da atividade realizada com os formadores regionais foram organizadas ações visando proporcionar a segurança para a aplicação de propostas do Caderno III, tendo como eixo central a aprendizagem de Ciências e sua significação para o aprendiz, abordando conceitos de demonstração, experimentação e investigação como práticas pedagógicas. Finalizamos evidenciando as reflexões, as perspectivas e os anseios dos professores sobre o ensino de Ciências.

\section{Palavras-chave:}

Contextualização do ensino. Ensino de Ciências. Formação continuada.

\section{Resumen:}

El “Pacto Nacional por el Fortalecimento de la Educación Secundaria (PNEM) es la articulación y coordinación de las acciones y estrategias entre la Unión y los gobiernos estatales en la formulación y aplicación de políticas para elevar el nivel de calidad de la escuela secundaria de Brasil". Fueron desarrolladas actividades de educación continua en las Ciencias Naturales, estas, estaban basadas en la conexion entre las acciones existentes e las nuevas proposiciones. A partir del análisis de la actividad llevada a cabo com los profesores regionales, fueran organizadas acciones para proporcionar seguridad para la ejecución de las propuestas del Cuaderno III, teniendo como punto central el aprendizaje de la Ciência e su significado para el alumno, abordando los conceptos de demostración, experimentación y investigación como prácticas pedagógicas. Terminados mostrando nuestras reflexiones, perspectivas e inquietudes de los profesores sobre la enseñanza de la Ciencia.

\section{Palabras-Ilave:}

Contexto de la educación. Enseñanza de las ciencias. Educación continua.

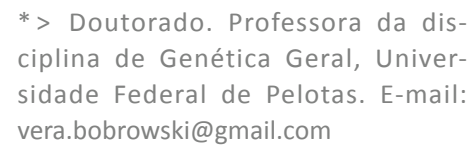

** > Doutorado. Professor da disciplina de Instrumentalização para o ensino de Ciências, CCQFA, Universidade Federal de Pelotas. E-mail: paulo.romeu55@gmail.com

*** > Doutorado. Professora da disciplina de Biologia Celular, Instituto de Biologia, Universidade Federal de Pelotas. E-mail: rosangelaferreirarodrigues@gmail.com

****> Doutorado. Professor da disciplina de Química Orgânica, CCQFA, Universidade Federal de Pelotas. E-mail: siqueiragm@gmail.com

Doutorado. Professora da disciplina de Genética, Instituto de Biologia Universidade Federal de Pelotas. E-mail: biahgr@gmail.com

Doutorado. Professora da disciplina de Biotecnologia, CDTEC, Universidade Federal de Pelotas. E- mail: lucianabicca@gmail.com 


\section{Introdução}

Entende-se que um dos principais objetivos da Educação Básica é levar os estudantes a construção de conhecimentos que os auxiliem na compreensão do mundo em que vivem. A perspectiva, a partir da qual se trabalha, é a de que tal compreensão determinará o modo como os estudantes se relacionarão com o mundo, não como mero coadjuvantes, mas como partícipes ativos e transformadores. Nesse sentido, também os professores devem estar preparados para o atendimento dessas demandas trazidas pelo estudante para a sala de aula.

Tornar-se professor é um processo de longa duração, de novas aprendizagens e sem um fim determinado. Para que se compreendam as práticas pedagógicas dentro das escolas é imprescindível conhecer o professor, sua formação inicial e como ele se (re) constrói ao longo da sua carreira profissional (NÓVOA, 1999).

Nesse contexto, a formação continuada pode possibilitar um novo sentido à prática pedagógica, contextualizar novas circunstâncias e resignificar a atuação do professor. Cresce a consciência de que é preciso ter um modelo formativo mais reflexivo que contemple práticas colaborativas. Isso é essencial para criar espaços de aperfeiçoamento, inovação e pesquisa nos quais sejam analisadas as dúvidas individuais e coletivas dos professores (IMBERNÓN, 2010).

Corroborando com a ideia de Martins (2001, p. 13) de que "[...] aquilo que os alunos apenas ouvem eles logo esquecem, daquilo que veem pouco guardam, mas aquilo que fazem e descobrem jamais esquecerão", foram desenvolvidas atividades de formação continuada em Ciências da Natureza alicerçadas nos pressupostos recomendados pelo Pacto Nacional pelo Fortalecimento do Ensino Médio (PNEM) utilizando-se dos conceito de demonstração, experimentação e investigação visando elevar o padrão de qualidade do Ensino Médio

\section{Os desafios no ensino de Ciências propostos pelo Pacto}

\section{Nacional pelo Fortalecimento do Ensino Médio (PNEM)}

Relatando um pouco a trajetória do GETEC (Grupo de estudos e trabalho em ensino de ciências), composto por professores da Universidade Federal de Pelotas, oriundos de áreas de pesquisa como a biotecnologia (manipulação genética e marcadores proteicos e moleculares), síntese química de compostos, histofisiologia reprodutiva e oleoquímica, que sempre tiveram a preocupação, como educadores, de "fazer o melhor" para que o educandos superassem suas dificuldades e acreditassem no seu potencial.

Trabalhando com cursos de licenciatura, temos o retorno dos nossos estagiários através de suas experiências nas escolas, com as práticas de docência, cujos relatos evidenciam a necessidade de uma maior aproximação entre universidades e escolas. Nesse sentido, o grupo tem atuado em formação continuada para atendimento da demanda de professores da Educação Básica dentro da área de ciências da Natureza e das nossas expertises. Diferentes projetos já foram realizados como: "Ciência na Escola", "Curso de Formação Continuada", "Sorrindo Verde", "Biotecnologia Invade a Escola", "Feira de Ciências", "Curso de Técnicas Histológicas e de Imunohistoquímica em Libras", "Vida de Inseto", entre outros.

Este contato direto com os professores nos diferentes municípios da região de abrangência da UFPel nos permitiu observar que a despeito da escassez de recursos, a criatividade e o empenho dos professores em ensinar, "do fazer diferente", garante a produção de excelentes práticas pedagógicas.
Essas experiências permitiram a atuação dos professores como formadores no Seminário Regional do PNEM. De acordo com os documentos orientadores do Ministério da Educação, o Pacto "[...] representa a articulação e coordenação de ações e estratégias entre a União e os governos estaduais na formulação e implementação de políticas para elevar o padrão de qualidade do Ensino Médio brasileiro" (BRASIL, 2014), ou seja, os agentes federais e estaduais pactuaram por um objetivo comum, o fortalecimento do Ensino Médio (EM), para tanto há necessidade do reconhecimento das fragilidades nesta etapa da Educação Básica e então, a partir disto, propor ações concretas de fortalecimento.

Algumas das fragilidades elencadas pelos professores durante as atividades do Pacto foram: a falta de investimentos materiais e em recursos humanos com ênfase na valorização dos professores, a evasão escolar e a ampliação do número de alunos com acesso ao EM. Como forma de atenuar algumas destas fragilidades, nosso grupo tem auxiliado na formação continuada docente da Educação Básica através de ações conjuntas, baseadas nas trocas de experiências na busca por respostas.

As ações de formação continuada tornaram-se uma importante ferramenta para promover o acompanhamento do fazer pedagógico frente às mudanças que a escola tem passado. Nessa mesma perspectiva, avaliamos o perfil atual dos nossos alunos e observamos que o domínio da tecnologia, os interesses, o uso da linguagem denotam mudanças significativas que fazem com que o ser professor e a própria escola necessitem de mudanças. E não a margem destas mudanças está o ensino das Ciências da Natureza, onde as novas tecnologias e as novas descobertas científicas impactam diretamente.

Esses conhecimentos estão presentes no cotidiano de todos nós professores, aluno e sociedade, porém o conteúdo escolar (conceitos) e a sua utilizaç̃o no dia a dia (aplicações dos conceitos) estão devidamente correlacionados? Como exemplo podemos referencia que, atualmente, muitos dos professores em sala de aula formaram-se antes de 1995, ano em que a internet deixou de ser restrita aos meios acadêmicos e científicos, passando a ser disponibilizada para acesso público.

Outra constatação durante as formações do PNEM é de que Ciências da Natureza (Física, Química e Biologia) é uma das áreas do conhecimento que mais reprova ou retém os alunos nesta etapa da Educação Básica, sendo considerada de difícil assimilação ou de conteúdos muito complexos. O PNEM tem oportunizado reflexões sobre a contextualização desses conhecimentos, a desfragmentação dos conteúdos e discussões sobre como realizar a interação entre os componentes do currículo.

O Pacto ainda nos convoca a refletir o ensino de forma geral, onde o professor deix de ser o protagonista detentor do saber na perspectiva tradicional de educação e torna o aluno o sujeito central no processo educativo Para iseo, precisamos conhecer os intesses e as necessidades dos educandos e, a partir desta percepção, repensar a organização de um trabalho pedagógico que vá ao encontro das Diretrizes Curriculares Nacionais para o Ensino Médio - DCNEM (BRASIL, 1998).

Na etapa inicial de formação do PNEM para Ciências da Natureza trabalhamos com os professores a contextualização e a interdisciplinaridade como ponto de partida para as reflexões. Os formadores regionais foram desafiados a desenvolverem atividades em grupo Caleno III. Foram uilizadas metodologias alte tendo a significação como palavra-chave, mostrando que o desafio e a desacomodação de conceitos são essenciais nesse processo. 


\section{Experimentação ilustrativa e investigativa}

\section{no ensino de Ciências da Natureza}

Antes de abordarmos os conceitos de experimentação e investigação no ensino de Ciências, cabe uma reflexão sobre as teorias de Piaget e Vygotsky a respeito da contrução do conhecimento pelos educandos, consideradas inicialmente como conflitantes por muitos educadores. Carvalho (2013), contudo, através de pesquisas em ambientes escolares, sugere ser este conflito inexistente, concluindo que o que ocorre é uma complementariedade de ideias.

Quando consideramos essas ideias para o ensino de Ciências, ressaltamos um ponto central dos estudos piagetianos, que é: "qualquer conhecimento novo tem origem em un conhecimento anterior". O que devemos fazer ao propor um novo assunto é reconhecer o que o aluno já sabe, e assim propor questões que propiciem a construção de novo conhecimentos. Como complementação deste processo de aprendizagem Vygotsky, em sua teoria, ressalta a importância da interação social na construção do conhecimento e o papel do professor na construção do novo.

No ensino de Ciências devemos proporcionar aos alunos condições para que a partir dos seus conhecimentos prévios (espontâneos ou adquiridos) e da situação problen proposta, eles construam as suas hipóteses e possam testá-las para resolução do problema. Através dos trabalhos em grupo observamos os efeitos da interação entre alunos e entre professor e alunos, e esta ação levando-os a reforçar a argumentação científica e então ao cientíca (CARVALHO, 2013, SASSERON, CARVA 2011).

Podemos categorizar as atividades nas aulas de Ciências. Carvalho (2013) conceitua as demonstraçoes investigativas como os problemas experimentais em que a ação é realzada pelo professor, pois oferecem perigo ao serem manipuladas pelos alunos. A expermentação segundo Giordan (1999) e Francisco Jr. et al. (2008) pode ser tanto ilustrativa como investigativa. A primeira é utilizada para reforçar conceitos já trabalhados em sala de aula sem que haja muita problematização e discussão dos resultados, enquanto que experimentação investigativa é empregada antes da conceituação e permite que os aluno obtenham informações que subsidiem a discussão, a reflexão e as explicações permitindo que estes não entendam apenas os conceitos, mas a forma de pensar Ciências no cotidiano.

Devemos considerar o fato de que muitos dos temas de Biologia não se adequan a uma experimentação direta e sim a observações, questionamentos e entrevistas. As atividades investigativas podem partir da leitura de um texto, sendo essencial a existência de um problema a ser resolvido, cabendo ao professor à ação de facilitador.

Esta prática do ensino de Ciências investigativo é enfatizada nos Parâmetro Curriculares Nacionais (BRASIL, 1998), porém segundo autores como Rodrigues e Borges (2008); Sá et al. (2007) e Zompero e Laburú (2011) o ensino de Ciências por investigação no Brasil ainda não está bem estabelecido, ressaltando fatores como as dificuldades dos professores em realizarem práticas de laboratórios ou atividades de investigação com os alunos, principalmente por se sentirem inseguros quanto ao gerenciamento da turma em função do número de alunos, pela ausência de infraestrutura ou até mesmo pela execução do experimento ou pela utilização de materiais de laboratório. Estas informações são ratificadas pela vivência do nosso grupo de trabalho nas várias escolas visitadas durante os cursos de formação continuada, onde presenciamos o sucateamento de escolas e tambén uma situação inversa, equipamentos modernos aos quais os professores não tinham a experiência necessária para o manuseio.

Ao propormos atividades de experimentação e investigação devemos ter em mente que os nossos alunos não formam uma categoria única. De acordo com os perfis categori- zados por Laburú e Arruda (2002) e retomados em suas considerações por Agostini et al. (2014), existem os seguintes alunos: os executores (qualquer atividade lhes é indiferente), os curiosos (são os que mais gostam de atividades experimentais), os cumpridores de tarefas (preferem um ensino convencional) e os sociais (preferem trabalhos em grupo). Nessa concepção os professores devem planejar suas atividades pensando principalmente em como direcioná-las para contemplar todos os alunos.

No modelo de atividades investigativas o aluno se depara com uma situação onde apenas lembrar-se de fórmulas, conceitos ou um exemplo anteriormente recebido não basta. Necessitarão escolher procedimentos, materiais, registro de dados, interpretação dos resultados e assim refletir e elaborar conclusões sobre a resolução do problema apresentado (BORGES, 2002).

Em contra ponto a essa postura, ou seja, o aluno deixando de ser receptor passivo do conhecimento, o professor também será desacomodado, mudando a maneira de pensar as suas aulas, propondo desafios, reflexões e passando a ser o mediador durante a investigação (AZEVEDO, 2004). Para este autor também, estas atividades investigativas podem ter diferentes formatos e não somente ser um experimento ou uma atividade de cerizará uma atividade investigativa será o caráter dado a ela em torno de um problema, é isso que permitirá ao aluno se tornar um participante ativo no seu aprendizado, buscando refletir, dialogar, emitir hipóteses, analisar e explicar, na busca de uma solução para o problema.

Porém não queremos dizer que não deverão ser realizadas aulas expositivas, muito pelo contrário, como citado por Krasilchik (2004) esta também pode ser uma modalidade ideal para introduzir e apresentar um tema ou para realização necessária de sínteses do conteúdo estudado.

Ressaltamos também a importância dos conceitos básicos para as atividades diferenciadas, pois só com a aquisição desses conhecimentos é que os alunos tornam-se independentes para, a partir de uma problemática, formular hipóteses, testá-las e então inferir resultados.

As atividades durante a formação no PNEM foram divididas em várias etapas, sendo o eixo central a aprendizagem de Ciências e sua significacão para o aprendiz. A partir deste tema discorremos sobre os conceitos de experimentação e investigação como práticas pedagógicas. Delizoicov et al. (2002) elencam os momentos pedagógicos e a experimentação como caminho pedagógico para o desenvolvimento de investigações contextualizadas e significativas aos alunos.

Utilizamos o exemplo apresentado no Caderno III, página 12, sobre germinacão de feijões, para análise sob diferentes olhares, visto ter sido este experimento um dos utilizados pelo astronauta brasileiro Marcos César Pontes, em 2006, na sua estada na estação espacial. Na educação infantil essa atividade pode ser realizada para investigação sobre a importância da água para os organismos. Nos anos iniciais, o foco da investigação pode ser os diferentes tipos de solo, enquanto nos anos finais serão, por exemplo, fotossíntese e respiração. No ensino médio aprofundam-se as questões com a metodologia científica, a elaboração de projetos e a associação dos conceitos de Química, Física e Biologia ligados ao experimento.

Abordamos também sobre as feiras de ciências como recurso didático. A maioria dos professores ao ser questionado sobre suas experimentações investigativas em tais eventos, ainda lembrava-se de detalhes, mesmo após transcorridos mais de 10 anos.

Conforme os professores foram se sentindo mais a vontade durante as atividades desenvolvidas, observamos que o espaço para esse intercâmbio de saberes é um dos pontos fortes e positivos do PNEM, não somente o período para discussões dentro da escola, mas também entre escolas, municípios e coordenadorias regionais. Consideramos que esse é um processo continuo de formação e, portanto novas ações que permitam a troca 
de ideias devam ser executadas de forma geral ou particulada, para que o PNEM atinja o sucesso esperado.

\section{A percepção e os anseios dos professores}

\section{no ensino de Ciências da Natureza}

Na primeira etapa da formação (momento 1), realizada com dez formadores das regionais educacionais, durante dois dias as atividades foram centralizadas na interdisciplinaridade, conforme trata o Caderno III da Etapa II do PNEM. Foi utilizado um eixo central a partir de um artigo com o tema "A cor da pele" (JABLONSKI; CHAPLIN, 2002) e sua contextualização nas diferentes áreas da Biologia, da Química, da Física e língua estrangeira. Utilizamos estratégias como: artigos científicos, experimentação, dramatização, internet e glossário, entre outras.

Entretanto, antes de promovermos essas ações, lançamos um desafio para estimular a participação dos formadores, com oito questões, sendo sete de múltipla escolh relacionadas e uma discursiva, cujas respostas estavam contidas no texto do artigo. As questões foram as seguintes:

1. A célula que produz o pigmento que propicia cor a pele é denominada de... 2 . A pele escura impede a destruição da...; 3 . As mulheres têm a pele mais clara que os homen por quê? 4 . As pessoas de pele escura que migram para regiões com baixa incidência solar podem apresentar... 5. As pessoas de pele escura possuem... 6. A evolução da pigmentação da pele está ligada a... 7. O pigmento que propicia cor na pele é denominado de... 8. Uma questão discursiva onde solicitamos que escrevessem algo que lembravam sobre pigmentação da pele e que não havia sido abordado nas perguntas anteriores.

Esta proposta corrobora a declaração de Rubem Alves, feita em 2014 : “A missão do professor não é dar respostas prontas. As respostas estão nos livros, estão na internet. $\mathrm{A}$ missão do professor é provocar a inteligência, é provocar o espanto, é provocar a curiosidade".

Salientamos que esse mesmo artigo havia sido utilizado em um projeto desenvolvido no município de Pelotas, com alunos do Ensino Médio, com excelentes resultados, os quais foram divulgados e discutidos com o grupo de formadores.

No prosseguimento das nossas atividades, as respostas ao desafio foram conferidas, organizadas em um gráfico e apresentadas (Figura 1). Após a divulgação dos resultados da atividade proposta, foi disponibilizado o artigo aos participantes. Observamos motivação e divertimento na leitura, através da curiosidade demonstrada na busca das respostas corretas e com a percepção de suas incorreções durante o desafio que pode ser ajustada, ou seja, algo "chato" pode ser prazeroso dependendo da atividade apresentada. Na sequência, foi solicitado que marcassem no artigo as palavras com significado desconhecido, para construção do dicionário ilustrado bilíngue (Figura 2).
Figura 1 - Número de acertos das questôes propostas no desafio apresentado aos formadores regionais

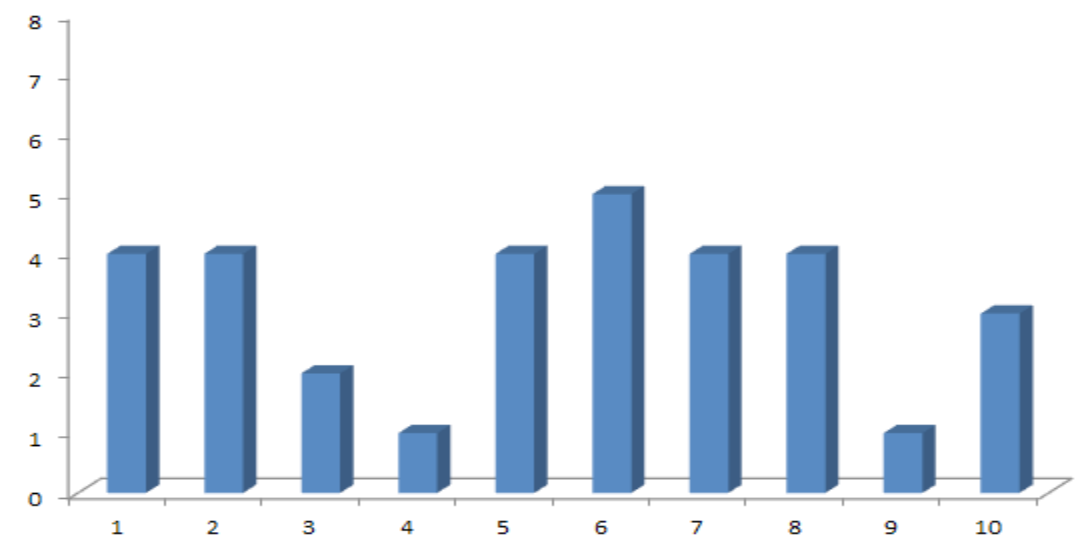

Fonte: Dados d p phe

Entretanto, devido ao tempo disponibilizado não foi possivel realizar a interdisciplinaridade conforme o planejado, com exposição de cada significado em português, sua escrita e pronúncia em espanhol e explicação biológica com a imagem. A insatisfação com relação a este ponto foi manifestada no questionário respondido pelos professores sobre as atividades, ao término do processo formação do PNEM, abordando aspectos negativos e positivos, transcrições a seguir:

"Ainda penso que o pacto precisa de mais tempo para discussões com os professores mas estamos caminhando para mudanças significativas".

"Gostaria que se estendesse por mais tempo, pois o trabalho é maravilhoso, mas os resultados são lentos no processo de formação dos professores e práticas pedagógicas". "Positivo; os projetos, a interdisciplinaridade, o espaço para discussão. Negativo perdemos muito tempo na escola discutindo os cadernos onde já poderíamos partir para a ação e o planejamento conjunto".

"Positivo: o fato de incentivar a discussão entre os professores de todas as áreas e a elaboração de novos projetos [...] Esta formação está sendo excelente, mas deveria ter ocorrido em setembro out outubro".

"Positivo é oportunizar o diálogo, a troca de experiências entre os colegas, mas falta tempo para reuni-los, tornando-se assim mais um momento de sobrecarga". 
Figura 2 - Glossário llustrado Bilíngue elaborado por um grupo de formadores
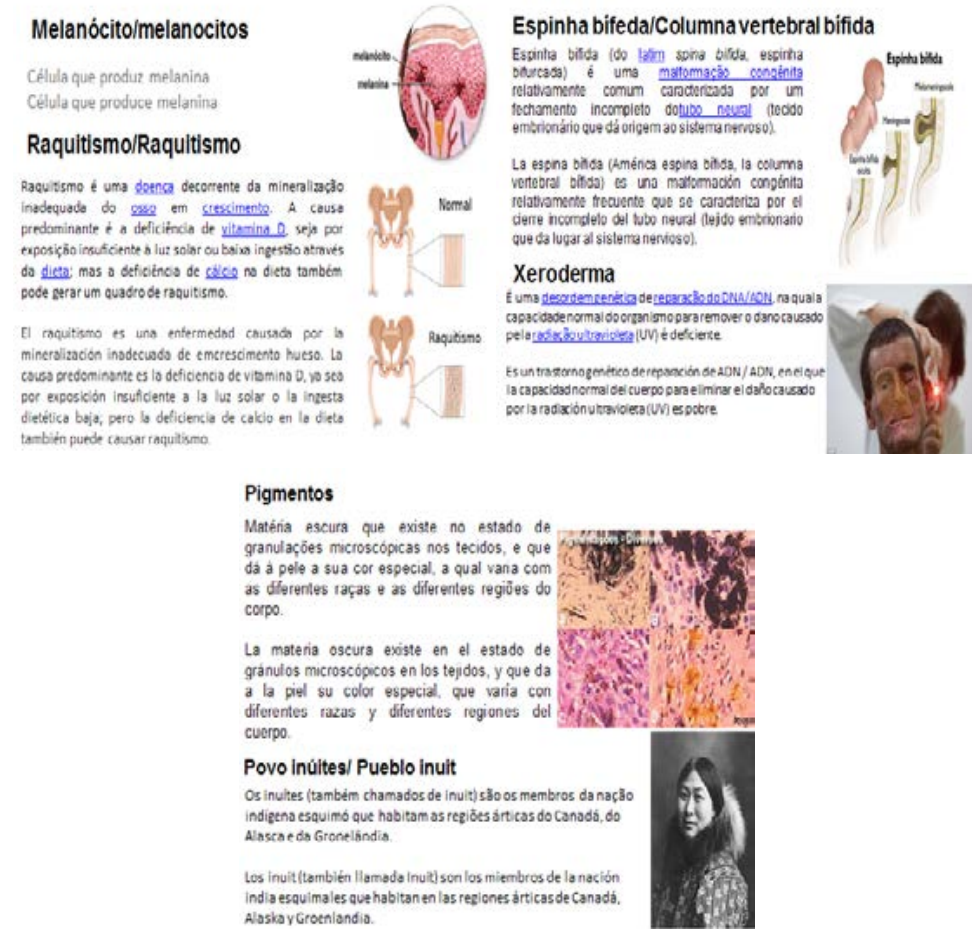

Fonte: Imagens free capturadas do Google.

Os formadores regionais também desenvolveram atividades relacionadas ao uso de metodologias alternativas como a construção de maquetes e jogos didáticos (Figura 3), como forma de exercitarem o trabalho em grupo e as interações que favorecem a negociação de significados, conforme apresentado no Caderno.

Após a execução de todas as atividades foi discutida a pertinência de tarefas semelhantes, como forma de incentivo para a apropriação do conhecimento, organização e exposição através de um trabalho em equipe (Figura 4).

Para a ampliação do conhecimento em assuntos específicos, tendo o professor como mediador, foram utilizados sites de busca visando o emprego em sala de aula, através da atividade de PBL (Problem Basic Learning - ensino através de problemas).

Figura 3 - Atividade de dobradura e jogos didáticos realizados durante o primeiro

encontro da área de Ciências da Natureza com os formadores regionais

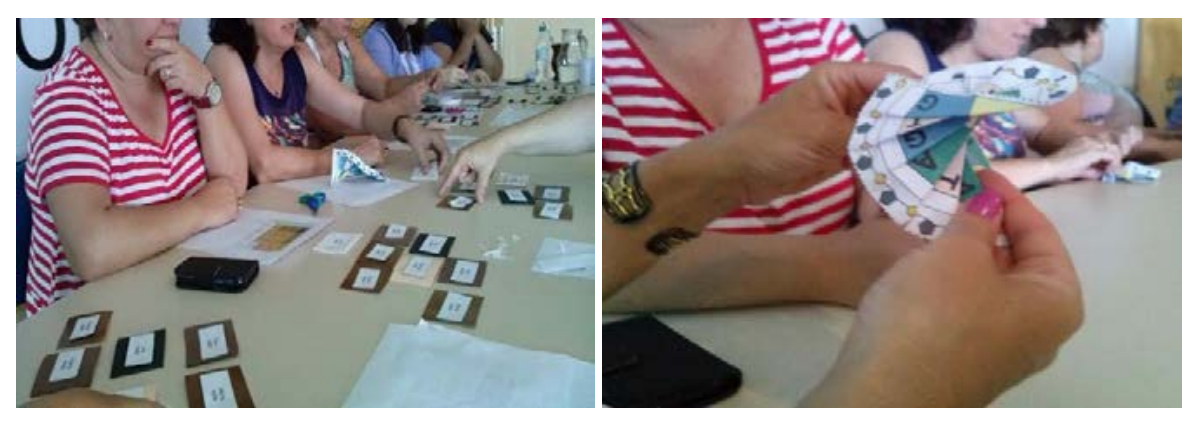

Fonte: Fotografias do acervo dos autores, Pelotas/RS, 2014.

Nesta atividade (PBL) salientamos a importância da apresentação dos conteúdo como um problema a ser resolvido, a fim de promover a desestabilização dos conhecimentos prévios, criando situações em que se estabeleça o conflito necessário para a aprendizagem.
Figura 4 - Discussão com formadores regionais sobre a pertinência das atividades e uso da tecnologia para tornar significativo o conhecimento

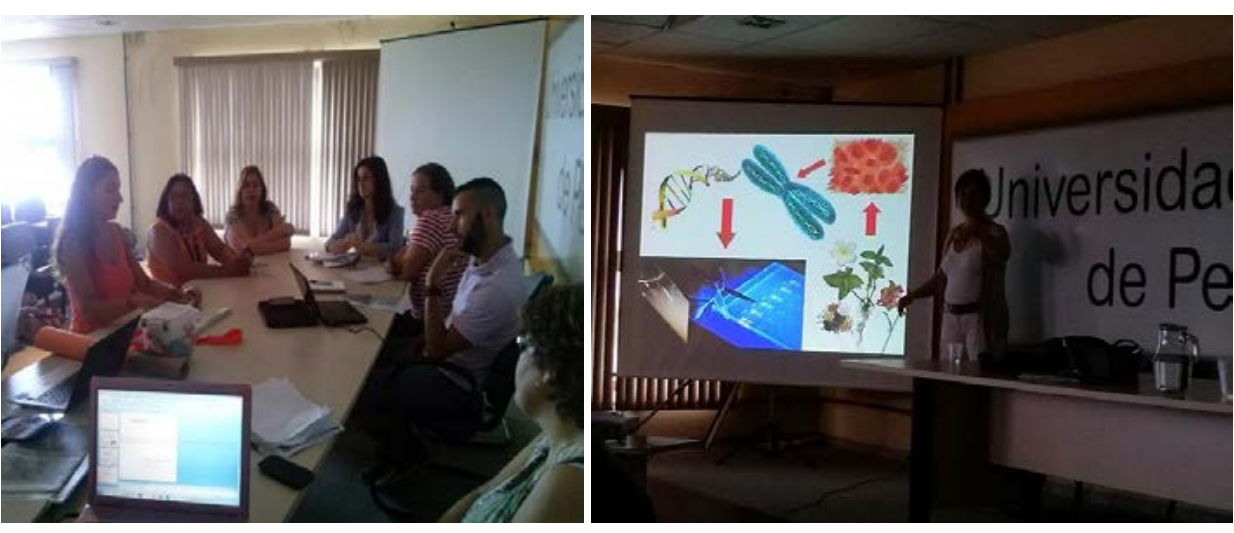

Fonte: Fotografias do acervo dos autores, Pelotas/RS, 2014

Segundo Piaget (1997) causar discordâncias ou conflitos cognitivos provoca desequilíbrios, possibilitando que o aluno, mediante atividades, reequilibre-se e supere a discordância, reconstruindo o conhecimento. Freire (2008, p. 35) salienta que o papel fundamental da escola é o de instigar de forma constante a curiosidade do educando em vez de "amaciá-la" ou "domesticá-la", destacando que: "Não haveria criatividade sem a curiosidade que nos move e que nos põe pacientemente impacientes diante do mundo que não fizemos, acrescentando a ele algo que fazemos".

Finalizamos a primeira etapa solicitando aos formadores a elaboração de ações interdisciplinares com temas atuais e de acordo com o contexto de cada escola. Essa proposta gerou insegurança nos formadores regionais, principalmente sobre as abordagens adequadas para cada região e em como fazer a apropriação do conhecimento exposto no Caderno de Ciências da Natureza, devido à maioria não possuir formação acadêmica nesta área. Entretanto, apesar da insegurança mencionada, observamos como aspecto positivo a disposição de todos em discutir e aceitar o proposto.

A percepção do grupo de formadores das Instituições de Ensino Superior é que esse processo ainda é muito incipiente, e que a diversidade de contextos também deve ser levada em consideração quando são propostas atividades desse porte, pois os conhecimentos prévios dos professores sobre a sua realidade de sala de aula são únicos, devendo ser o ponto de partida para mudanças.

\section{Seminário Regional III - Atividades com os orientadores de estudo}

A partir da análise das atividades realizadas com os formadores (momento 2), reorganizamos as nossas ações visando proporcionar a segurança necessária para aplicação das propostas do Caderno de Ciências da Natureza, para os aproximadamente 200 professores orientadores de estudo participantes do evento. As atividades foram divididas em várias etapas, sendo a aprendizagem de Ciências e sua significação para o aprendiz o eixo central. As atividades sobre os conceitos de experimentação e investigação, como práticas pedagógicas estão apresentadas na figura 5 . 
Figura 5 - Atividades propostas nas oficinas de formação do pacto. A) Professores em atividade de investigação; B) Professores em atividade de experimentação

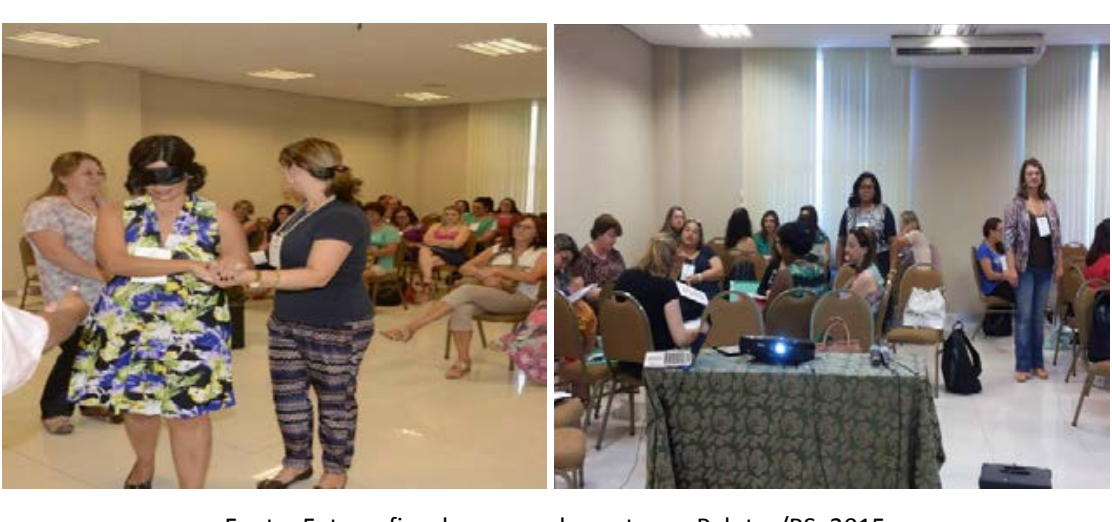

Fonte: Fotografias do acervo dos autores, Pelotas/RS, 2015.

Como citado anteriormente, elencamos os momentos pedagógicos de Delizoicov et al. (2002) e a experimentação como caminho pedagógico para o desenvolvimento de investigações contextualizadas e significativas aos alunos. Apresentamos tópicos para incentivar o envolvimento pela busca de mudanças e aplicação das metodologias alternativas, indicadas no Caderno, e mostramos soluções práticas para contornar dificuldades.

Todas as atividades foram realizadas em grupos, para mostrar a importância de tornar usual essa prática, pois atividades em grupo permitem desenvolver a troca, o espírito colaborativo e a socialização (SANT'ANA; RAMOS, 2009). Percebemos no depoimento de alguns professores, transcritos abaixo, que entendem que a educação é um processo contínuo, no qual o intercâmbio de ideias e compartilhamento de anseios e perspectivas, entre professores dos diversos segmentos, possibilita aprimorar esse processo.

"Boa oportunidade pra aprendermos práticas pedagógicas diferentes, compartilhar experiências e criar a possibilidade de trocar essas práticas para que a aprendizagen se torne significativa...."

"Ótima oportunidade de os professores se encontrarem, debaterem e se aperfeiçoarem nas suas diferentes áreas, trabalhando e aprendendo com a interdisciplinaridade". "Esse tipo de projeto é fundamental, pois visa os professores que estão na escola e não tem tempo pra se aprimorar em função da carga horária excessiva e da falta de liberação".

“É importante, pois dá acesso a novos conhecimentos, principalmente por ser tran mitido pela equipe de uma Universidade que busca, na pesquisa, alternativas de melhoria do trabalho dos educadores"

"É necessário, pois nos traz novas formas de trabalho, troca de ideias e reformulações"

"Muito bom, oportuniza reuniões, debates, mexe com as pessoas e principalmente com os acomodados"

Realizamos também atividades nas quais procuramos transmitir a diferença existente no processo de aprendizagem do aluno, do envolvimento através de desafios (Figura 6 ). Mostramos que esses desafios podem ser realizados de formas diversas, somente modio dicico e de textos info a do livro didático e de textos informativos, de forma exploratória, para apropriação do conhecimento.

Utilizamos erros contidos em CDs disponibilizados com o livro didático, como forma de desafio a capacidade de discernimento e compreensão de fenômenos de cad aluno. Demostramos a utilização de softwares como forma de facilitar o entendimento de processos fisiológicos, através da contextualização e demonstração geral do processo, quebrando dessa forma a barreira à compreensão, gerada pela fragmentação. Mostramos como podem elaborar softwares, com recursos de armazenamento de informações, que servirão de base para avaliação e ajustes no processo de ensino-aprendizagem.

\section{Figura 6 - Professoras da UFPEL apresentando metodologias alternativas no III Semi-} nário Regional do PNEM

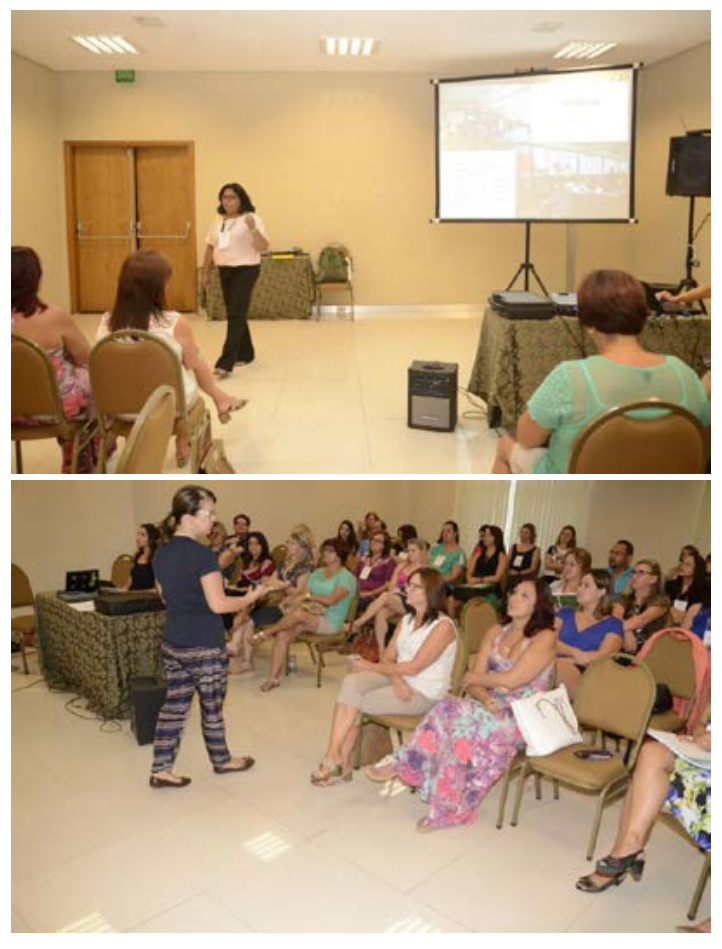

Fonte: Fotografias do acervo dos autores, Pelotas/RS, 2015

Salientamos a importância da experimentação e as soluções para os problemas de laboratórios utilizados como depósitos e para a falta de auxiliares em turmas com muitos alunos. Apresentamos projetos de revitalização de laboratórios, utilizando o apoio de estagiários para recuperar áreas abandonadas. Para sanar o problema de falta de pessoal de apoio nas atividades práticas, descrevemos o projeto "Aluno Ensinando Aluno", que possibilita aproveitar a colaboracão de alunos atuando em turno inverso, promovendo intercâmbio, encorajamento e motivação para prosseguir em uma carreira acadêmica.

Após apresentação das metodologias alternativas salientamos a necessidade de adaptação à realidade atual, que exige combinar imaginação e ação com capacitação na busca de novas informações. Exige saber trabalhar com recursos modernos da informática, que

Contudo, o grande problema apontado por alguns professores, ainda continua sendo a falta de tempo para o planejamento de ações interdisciplinares, devido as suas elevadas cargas horárias.
"Esse tipo de projeto éfundamental, pois visa os professores que estão na escola e não tem tempo pra se aprimorar em função da alta carga horária e da falta de liberação" "[...] infelizmente há professores que trabalham em outras escolas, o que torna os encontros com todo corpo docente, muitas vezes, inviável".
"[...] procuro, porém não consigo relacionar com a maioria, pois cada professor atua numa mesma área e com diferentes turmas e diferentes componentes curriculares e relacionar os conteńdos programáticos livros didáticos e assuntos comuns nos áreas. Já tentei víris vezes e aind não consegui conforme desejuna mas dentro da

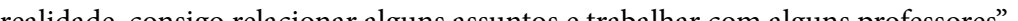


"É essencial, mas a organização curricular e a distribuição de recursos humanos en múltiplas escolas barram o trabalho pedagógico. O professor está sobrecarregado"

Entretanto, percebemos através de algumas declarações que determinadas escolas conseguiram se adaptar e sanar esse problema, com a modalidade do Ensino Politécnico.

O Politécnico veio para organizar esta ferramenta de melhoria para que atinjamos a prendizagem de forma plena. Através dos encontros criamos estratégias e montamos projetos significativos para a construção do conhecimento"

"O pacto contribuiu, junto com a disciplina de seminário integrado, para repensarmos nossa prática e nossas atividades. Como sou professora de Física, facilmente participo de atividades propostas por outras áreas".

dificuldade maior era encontrar com os colegas das outras áreas para planejar as ç̧oes. Agora essa dificuldade não existe, pois temos este momento garantido, o que torna o trabalho mais efetivo. Estamos caminhando para melhorar cada vez mais, embora ainda alguns colegas resistam à ideia da interdisciplinaridade".

Sobre o PNEM, como política pública de governo para a formação continuada de professores da rede pública, a grande maioria das respostas evidencia aprovação, outra mostram que são necessárias algumas adaptações para que este processo se torne realmente efetivo.

“É um bom começo, pois a atualização do professor é necessária. Ótima aplicação do dinheiro público. Deve continuar e ser oferecido também aos diretores das escolas.

"É o caminho para seguirmos qualificando nossa prática. A formação continuada e permanente é necessária para trabalharmos com esse público que está em busca de identidade, afirmação e que traz perspectivas de vidas (e histórias) diferenciadas. O PACTO vem demonstrando mudança de posturas e maior compro
Excelente iniciativa e que mostra compromisso. Espero que continue!"

Vem para mudar a forma de pensar, práticas atrasadas e vem de encontro à realidade atual de forma a construir verdadeiros cidadãos críticos e capazes de satisfazer o mercado de trabalho cada vez mais exigente. Formar um cidadõ que se adpte a realidades onde está inserida contribuindo no desenvolvimento da sociedade".

"Oportunidade de desenvolver maior interesse dos educandos sobre aprendizagen, tornando-a mais significativa e trazendo resultados positivos para a educação".

"Importante oportunidade para os professores se atualizarem e qualificarem o processo de ensino com vistas a uma melhor aprendizagem?

extremamente significativo para educação e para qualificação dos profissionais da area. A cada curso de formação e/ou seminario voltamos com energias renovadas para retomar nosso trabalho nas escolas?

"Excelente oportunidade para refletir, repensar sobre posturas e práticas pedagógicas ao mesmo tempo aplicar ideias inovadoras. Penso que deveria ser um programa contínuo e permanente"

"Seria muito melhor se não nos dessem materiais prontos, "ideias concebidas", pois estamos discutindo algo que está dado e que só nos resta acatar. Deveria ser un programa que desse voz e ouvidos aos professores e o que julgam importante para educação."

Finalizamos com a certeza de que essas atividades despertaram o interesse em continuarmos inovando a nossa prática e instigando os docentes da Educação Básica para o uso de metodologias que tornem o ensino de Ciências da Natureza desafiador e prazeroso.

\section{Considerações finais}

As discussões evidenciaram que a grande maioria dos professores está envolvida nesse processo de mudança. Entretanto, é necessária uma postura colaborativa entre a equipe de professores nas escolas para produzir um ambiente de intercâmbio e comunicação no qual eles possam colocar e reconstruir suas ideias e capacidades pedagógicas para projetar e desenvolver esquemas alternativos que promovam melhoria do processo de ensino e aprendizagem.

Percebemos que os professores aproveitaram esse momento para renovar sua determinação em buscar formas de tornar mais efetivo seu trabalho. Isso ficou evidente na forma entusiástica que procuraram estabelecer contatos, articular ações e planejar trabalhos. Observamos o envolvimento nas atividades com a leitura do Caderno III e nossa relação prática com seus tópicos, e que captaram a importância de promover a desestabilização dos conhecimentos prévios, através de desafios para o aluno. Entretanto o período reduzido não possibilitou que explorássemos mais as várias possibilidades que as Ciências da Natureza proporcionam.

As atividades desenvolvidas resultaram em várias propostas de visitas às escolas e coordenadorias regionais, indicando que os formadores ainda não se encontram totalmente seguros para aplicação das atividades que o PNEM propõe. Consideramos que esse é um processo continuo de formação e, portanto novas ações devem ser executadas de forma geral ou particulada, até que eles se sintam aptos e embasados para que o PNEM atinja o sucesso esperado.

\section{Referências}

AGOSTINI, Vanessa W.; TREVISOL, Maria T. C. Experimentação didática no ensino de ciências: uma proposta construtivista para utilização do laboratório didático. In: COLÓQUIO INTERNA-
CIONAL DE EDUCACÃO, IV. 2014 Joaçaba. Anais.. Joaçaba: UNOESC, 2014 p. 753-762.

AZEVEDO, Maria C. P. S. Ensino por investigação: problematizando as atividades em sala de

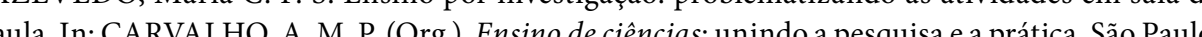
Pioneira Thomson Learning, 2004 .
Pino de ciências: unindo a pesquisa e a prática. São Paulo: BORGES, Tarciso A. Novos rumos para o laboratório escolar de ciências. Caderno Brasileiro do Ensino de Física, Florianópolis, v. 19, n. 3, p. 291-313, dez. 2002.

BRASIL. Secretaria de Educação Básica. Formação de professores do ensino médio, Etapa II, Caderno III: Ciências da Natureza. Curitiba: UFPR/Setor de Educação, 2014. 48 p.

_. Parâmetros Curriculares Nacionais: Adaptaçôes Curriculares. Brasilia, DF, 1998. Disponível em: <www.educacaoonline.pro.br/adaptacoes_curriculares.asp>. Acesso em: 10 maio 2016.

CARVALHO, Anna M. P. de. O ensino de ciências e a proposição de sequências de ensino investigativas. In: CARVALHO, Anna Maria Pessoa de (Org.). Ensino de ciências por investigação: condição para implementação em sala de aula. São Paulo: Cengage Learning, 2013. p. 1-20

DELIZOICOV, D.; ANGOTTI, J. A.; PERNAMBUCO, M. M. Ensino de Ciências: fundamentos e métodos. São Paulo: Cortez, 2002.

FRANCISCO JÚNIOR, Wilmo E.; FERREIRA, Luiz H.; HARTWIG, Dácio R. Experimentação Problematizadora: Fundamentos Teóricos e Práticos para a Aplicação em Salas de Aula de Ciências. Såo Paulo: Sociedade Brasileira de Química, 2008. p. 34-41.

REIRE, Paulo. Pedagogia da autonomia. São Paulo: Editora Paz e Terra, 2008

GIORDAN, Marcelo. O papel da experimentação no ensino de ciências. Quimica Nova na Escola, São Paulo, n. 10, p. 43-49, nov. 1999.

IMBERNÓN, Francisco. Formação continuada de professores. Porto Alegre: Artmed, 2010. 
JABLONSKI, Nina; CHAPLIN, George. Todas as Cores da Pele. Scientific American Brasil, São Paulo, ano 1, n. 6, p. 64-71, nov. 2002.

KRASILCHIK, Myriam. Prática de ensino de biologia. 4. ed. São Paulo: Edusp, 2004.

LABURÚ, Carlos E.; ARRUDA, S. de M. Reflexões criticas sobre estratégias instrucionais construtivistas na educação científica. Revista Brasileira do Ensino de Física, São Paulo, v. 24, n. 4, p. 477-488, dez. 2002.

MARTINS, Jorge S. O trabalho com projetos de pesquisa. 8. ed. Campinas: Papirus, 2011.

NÓVOA, António (Org.). Os professores e a sua formação. Portugal: Porto, 1992.

PIAGET, Jean. A Psicologia da Criança. Porto: Asa, 1997.

RODRIGUES, Bruno A.; BORGES, Tarciso A. O Ensino de Ciências por Investigação: Reconstrução Histórica. In: ENCONTRO DE PESQUISA EM ENSINO DE FÍSICA, XI., Curitiba, 2008. Anais... CD-ROM. Curitiba: SBF, 2008. p. 1-12.

SÁ, Luciana P.; FRANCISCO, Cristiane A.; QUEIROZ, Salete L. Estudos de caso em química. Química Nova, São Paulo, v. 30, n. 3, p. 731-739, 2007.

SANT'ANA, Ilza M.; RAMOS, Heloisa C. Avaliação: ela ajuda a orientar a aprendizagem. Disponível em: <http://revistaescola.abril.com.br/planejamento-e-avaliacao/tabela_avaliacao_024.html $>$. Acesso em: 21 set. 2009.

SASSERON, Lucia H.; CARVALHO, Anna M. P. de. Construindo argumentação na sala de aula: a presença do ciclo argumentativo, os indicadores de alfabetização científica e padrão de Toulmin. Ciência e Educação, Bauru, v. 17, n. 1, p. 97-114, 2011.

ZOMPERO, Andreia F.; LABURÚ, Carlos E. Atividades Investigativas no Ensino de Ciências: aspectos históricos e diferentes abordagens. Revista Ensaio, v. 13, n. 3, p. 67-80, set./dez. 2011. 